\title{
Comparison of fixed area and distance sampling methods in open forests: case study of Zagros Forest, Iran
}

\author{
Mehrdad Mirzaei $^{1} \cdot$ Amir Eslam Bonyad ${ }^{1}$
}

Received: 9 March 2014 / Accepted: 3 June 2015/Published online: 23 April 2016

(C) The Author(s) 2016. This article is published with open access at Springerlink.com

\begin{abstract}
The main aim of this study was to evaluate methods for fixed area and distance sampling in the Zagros open forest area in western Iran. Basic forest management and planning required appropriate quantitative and qualitative information. Two sampling methods were compared on the basis of the actual means of characteristics derived from the $100 \%$ survey. In total, 37 sampling plots were systematically installed with a grid of $100 \mathrm{~m} \times 100 \mathrm{~m}$ in the study area. Density, crown canopy, and basal area of the stands were measured. The $100 \%$ survey showed that tree density above $12.5 \mathrm{~cm}$ diameter at breast height was $68.04 \mathrm{stem} \mathrm{ha}^{-1}$, basal area was $15.16 \mathrm{~m}^{2} \mathrm{ha}^{-1}$ and crown canopy percentage was $35.71 \% \mathrm{ha}^{-1}$. The values for the traits determined by the two sampling methods differed significantly $(P=0.05)$. When the time required for the methods was compared, transect sampling required less than systematic-random sampling. Therefore, the transect sampling method was the more economical method for the Zagros open forests. The transect sampling method was statistically defensible and practical for quantitating characteristics of the Zagros open forests.
\end{abstract}

Keywords Ilam - Systematic random sampling - Transect sampling $\cdot$ Zagros Forest

The online version is available at http://www.springerlink.com

Corresponding Editor: Yu Lei

Mehrdad Mirzaei

mehrdadmirzaei28@gmail.com

1 University of Guilan, Sowmeh Sara City, Guilan, Islamic Republic of Iran

\section{Introduction}

The Zagros open forests in western Iran cover 5 million ha at low density. Natural regeneration is nearly non-existent, and severe soil erosion exposes the source rock (MarviMohajer 2007). To survey stand characteristics of these forests, low-cost sampling methods with acceptable accuracy are needed. In most cases, the sampling method should accommodate the type of forest and suit the management aims for the forest (Bonyad 2015). Both data sampling and analysis need to be accurate enough to increase efficacy for a full-calipering inventory. The best sampling techniques provide accurate and representative information about the population studied, while being geometrically compact and requiring the least amount of field effort (Laycock and Batcheler 1975; Parker 1979; Scott and Gove 2002). Distance sampling methods, long used for forest inventories (Kleinn and Vilcko 2006; Bonyad 2015) are popular where plot (quadrat) sampling is difficult or too costly (Hall 1991; Lessard et al. 2002; Sheil et al. 2003; Picard et al. 2005). A fixed area square quadrat has traditionally been used for vegetation sampling (Clapham 1932). Other shapes of fixed area plots, such as rectangular or circular plots, and belt transects, have been used to improve habitat coverage and the ease of use (Barbour et al. 1987). Nimvari et al. (2004) compared systematic random sampling with circular plots and transect sampling methods in the Zagros Forest and the results showed that the transect method was more suitable for estimating density, crown canopy and basal area characteristics. When Pique et al. (2011) compared the accuracy of estimated means for basal area, stand density, and diameter class distribution in forest stand inventories, they found that the Bitterlich Relascope more accurately estimated basal area than density in stands with multiple strata 
and open structures, while the reverse was true for fixed radius plots. Evaluating the efficiency of the systematic random (rectangular plot), transect, strip, and stratification sampling methods in an oak forest in northern Iran, Fallah et al. (2012) found that the transect method was the most appropriate inventory method for this forest based on $(\mathrm{E} \%)^{2} \times T$, where $\mathrm{E} \%$ is the percentage of sampling error and $T$ is total inventory time. The main aim of this study was to evaluate the suitability of fixed area and distance sampling methods for an inventory of the Zagros open forest areas in western Iran to determine a statistically defensible and practical sampling method to quantitate stand characteristics of the Zagros open forests of Iran. For this purpose, the systematic random sampling method with fixed area and transect sampling method with a fixed number of trees were compared. The results of the two sampling methods were compared with the actual mean of these quantitative characteristics level derived from a $100 \%$ survey. The concept of an easy and quick survey to obtain quantitative and qualitative information about the Zagros open forests is also proposed.

\section{Materials and methods}

\section{Study area}

The study area was 37.2 ha, located between $46^{\circ} 22^{\prime} 40^{\prime \prime} \mathrm{E}$ and $46^{\circ} 23^{\prime} 30^{\prime \prime}$ E longitude and $33^{\circ} 42^{\prime} 05^{\prime \prime}$ and $33^{\circ} 42^{\prime} 40^{\prime \prime}$ latitude (Fig. 1). The original vegetation of the study area was an uneven-aged mixed forest dominated by Quercus brantii, mixed $Q$. brantii-Pistacia atlantica-Acer

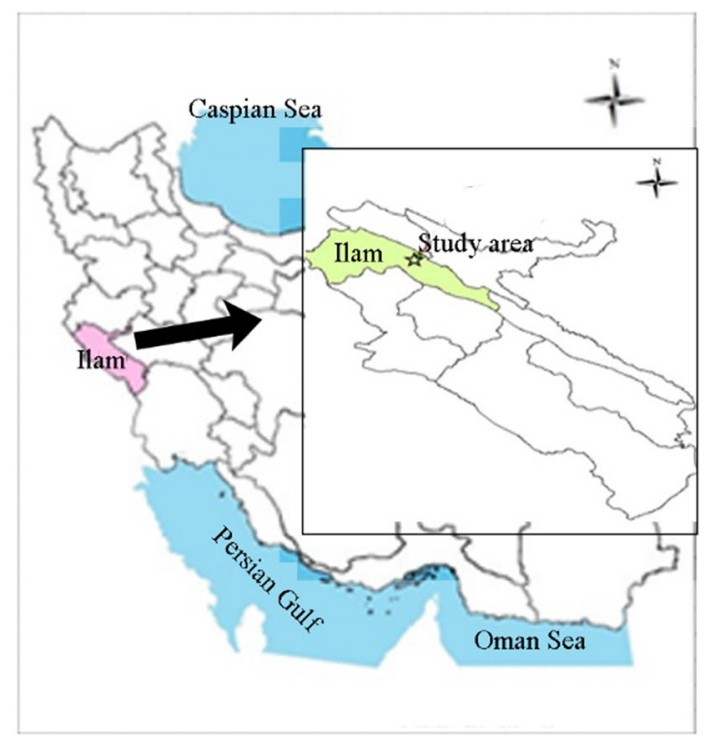

Fig. 1 Study area cinerascens, and mixed Daphne mucronata-Amygdalus orientalis (Rostami and Heidari 2009). This area has a semi-humid cold climate based on the DeMartonne climate classification; the Emberger climate classification rates the climate as semi-arid (Rostami and Heidari 2009; Mirzaei and Bonyad 2014).

\section{Methods}

Full-calipering inventory (100\% survey) method

All trees in the forest stand with diameter at breast height $(\mathrm{DBH})$ greater than $12.5 \mathrm{~cm}(\mathrm{DBH}>12.5 \mathrm{~cm})$ were measured in a $100 \%$ survey. To simplify the $100 \%$ survey, the study area was divided into plots of 0.5 ha $(100 \mathrm{~m} \times 50 \mathrm{~m})$. Data for each plot was recorded separately, and variables for each tree were recorded: species, $\mathrm{DBH}$, and diameters of canopy (maximum and minimum diameters).

Transect sampling method with fixed numbers of trees

A transect sampling method with fixed numbers of trees was used to estimate variables with low density in the Zagros open forest as recommended in different sources (Krebs 1999; Newton 2007; Sutherland 2008). The starting point of each transect, that is, the location of the first tree, was determined in the field, and species, DBH, and diameters of canopy (maximum and minimum diameters) of the first tree were measured. The same approach was used for each tree (crown or trunk) encountered on the transect, and the distance from the previous tree was also measured and recorded, until five trees in transect had been measured. In total, 37 sampling plots were systematically installed (a grid of $100 \mathrm{~m} \times 100 \mathrm{~m}$ ) in the study area (Fig. 2). The equations used to calculate density per hectare, crown canopy (\%), and basal area per hectare (Zobeiri 2007) are described in Table 1.

\section{Systematic random sampling method}

A systematic random sampling method within a fixed area $\left(1000 \mathrm{~m}^{2}\right)$ was also used. The grid of the systematic random sampling method was $100 \mathrm{~m} \times 100 \mathrm{~m}$, and 37 rectangular plots (each $25 \mathrm{~m} \times 40 \mathrm{~m}$ ) were established (Fig. 2). All tree characteristics were measured in each plot. The equations below were used to calculate statistical parameters for each variable measured (Zobeiri 2005; Bonyad 2015):

$$
\bar{x}=\frac{\sum x_{i}}{n},
$$



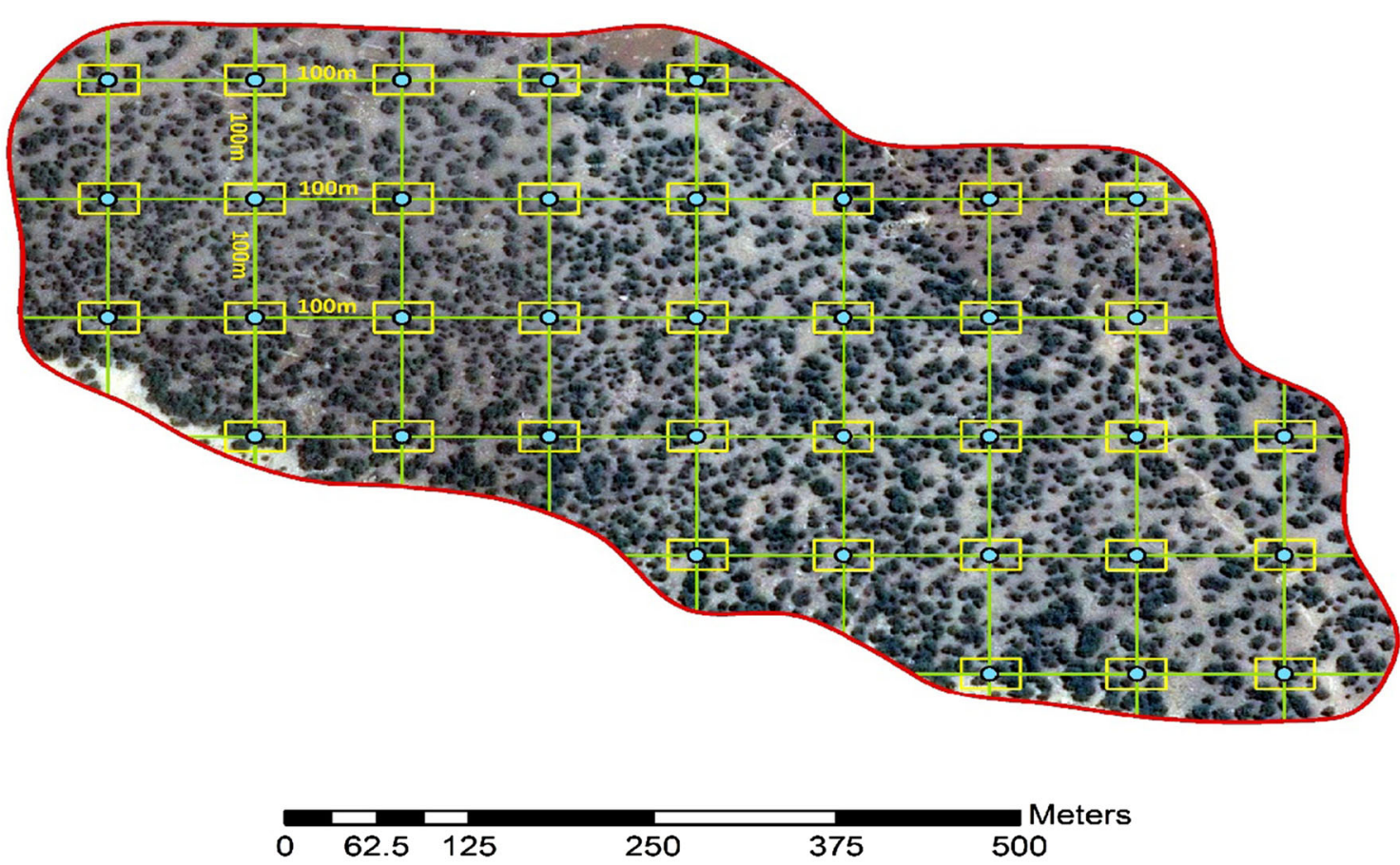

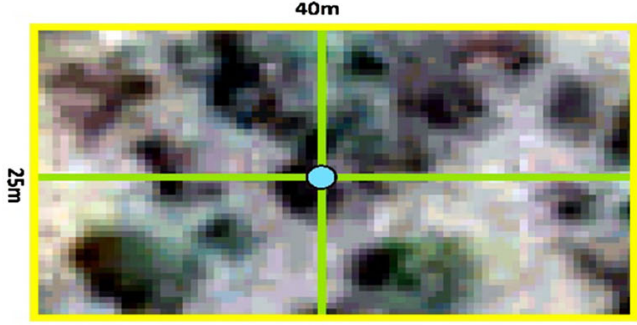

Rectangular plot

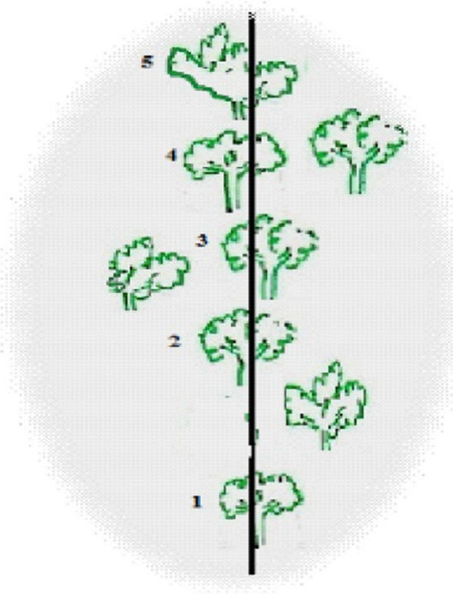

Transect

Fig. 2 Inventory network, rectangular plot and transect sampling

Table 1 Equations for calculation of characteristics

\begin{tabular}{ll}
\hline Characteristics & Equations \\
\hline Density (per hectare) & $\bar{a}=\frac{\left(a_{1}+a_{2}+a_{3}+a_{4}\right)}{4}, N=\frac{10,000}{\bar{a}^{2}}, \bar{N}=\frac{\Sigma N}{n}$ \\
Crown canopy $(\%)$ & $\overline{\mathrm{CA}}=\frac{\frac{\pi}{4} \times \Sigma\left(\mathrm{CD}_{1} \times \mathrm{CD}_{2}\right)}{5}, \mathrm{CC} \%=\frac{\overline{\mathrm{CA}} \times 100}{\bar{a}^{2}}, \overline{\mathrm{CC}} \%=\frac{\Sigma \mathrm{CC} \%}{n}$ \\
Basal area $\left(\mathrm{m}^{2} \mathrm{ha}^{-1}\right)$ & $g=\frac{\pi}{4} d^{2}, \bar{g}=\frac{\Sigma g}{5}, G=\bar{g} N, \bar{G}=\frac{\Sigma G}{n}$ \\
\hline
\end{tabular}

$\overline{\bar{a}}$ Mean distance between trees at each transect, $N$ number of trees ha ${ }^{-1}$ at each transect, $\bar{N}$ mean number of trees ha ${ }^{-1}$ in the forest stand, $n$ number of transects measured, $\overline{C A}$ mean of tree crown canopy on each transect, $C D_{1}, C D_{2}$ minimum and maximum diameter of tree crown $(\mathrm{m}), C C$ crown canopy trees at each transect (\%), $\overline{C C}$ mean of crown canopy in forest stand (\%), $g$ basal area for a tree, $d$ diameter at breast height, $\bar{g}$ mean of basal area at each transect, $G$ basal area ha ${ }^{-1}, \bar{G}$ mean of basal area in forest stand 
$S_{x}=\sqrt{\frac{\Sigma X_{i}^{2}-\frac{\left(\Sigma X_{i}\right)^{2}}{n}}{n-1}}$

$S_{\bar{x}}= \pm \frac{S_{x}}{\sqrt{n}}$,

$E= \pm t S_{\bar{x}}$

where $\bar{x}$ is the mean of variable $x, n$ is the number of plots, $x_{i}$ is the value for $i$ th tree, variables, $S_{x}$ is the standard deviation (SD) of variables, $S_{\bar{x}}$ is the standard error, $E$ is the sampling error and $t$-value is dependent to probability level and number of plot.

Kolmogorov-Smirnov test were used for the normality test of dada. An analysis of variance and $t$ test were used to compare statistical parameters for the different sampling methods. Excel ver. 2013 (Microsoft Office) and IBM SPSS Statistics ver. 22 software were used to compared differences between the measured data.

\section{Time studies}

Time studies are important in forest inventory (Heidari et al. 2009). The estimator $(\mathrm{E} \%)^{2} \times T$ for the sampling methods, was used to determine the most economical and fastest survey method for estimating stand variables (Loetsch et al. 1973; Husch et al. 1982). Thus, the method with the lowest $(\mathrm{E} \%)^{2} \times T$ is the most economical for ease and speed.

\section{Results}

The results of this study indicated that, the original vegetation in Zagros open forests area comprised uneven-aged mixed stands dominated by $Q$. brantii var. persica and $D$. mucronata-A. orientalis. The Kolmogorov-Smirnov test indicated that the data for the study area were consistent with a normal distribution. The results of the $100 \%$ survey are shown in Table 2.

The stand variables for the 37 sample plots were measured and analyzed with systematic random sampling method with a fixed area $\left(1000 \mathrm{~m}^{2}\right)$ and transect sampling methods. The results of statistical parameters showed in Table 3.

Table 2 Results of the $100 \%$ inventory

\begin{tabular}{llll}
\hline Characteristics & Actual mean & SD & CV (\%) \\
\hline Density $\left(\right.$ tree $\left.\mathrm{ha}^{-1}\right)$ & 68.043 & \pm 32.807 & 48.215 \\
Basal area $\left(\mathrm{m}^{2} \mathrm{ha}^{-1}\right)$ & 15.108 & \pm 8.975 & 59.456 \\
Crown canopy (\%) & 35.713 & \pm 14.481 & 40.548
\end{tabular}

$\mathrm{CV}$ coefficient of variation
The results indicated that the $\mathrm{SD}$ of $\mathrm{DBH}$, basal area and crown canopy (\%) in the transect sampling method was lower for each variable than in the systematic-random sampling method. The mean $(\bar{x})$ for the two sampling methods was compared using the paired $t$-test. The results showed that the values obtained by two sampling methods differed significantly different $(P=0.05$; Table 4$)$.

The mean DBH, basal area and crown canopy (\%) derived from the systematic random sampling and transects sampling methods were compared with the actual mean of these variables derived from the $100 \%$ inventory. The results indicated that two sampling methods differed significantly from the actual mean (Table 5).

When the two sampling methods were compared using the estimator $(\mathrm{E} \%)^{2} \times T$ the estimator $(\mathrm{E} \%)^{2} \times T$ for the transect sampling method was lower than for the systematic-random sampling method. Therefore, transect sampling method was more economical for the Zagros open forests (Table 6).

\section{Discussion}

The main advantages of the Zagros Forests that known as open forests are water supply, soil conservation, climate alternation and various intangible social benefits that are frequently termed as forest influence. For quantitating characteristics in these open forests, sampling methods need to be low cost with acceptable accuracy. The actual means of traits measured in the $100 \%$ survey were used as the criteria for comparing values from the systematic random plot sampling with those from the transect sampling method, which was based on a fixed number of stems. The SD of DBH, basal area and crown canopy (\%) in the transect sampling method were lower than for the systematic-random sampling perhaps due to variation within and between plots in the systematic-random sampling method because the forest stands of study area were open forests with very low density, basal area and crown canopy (\%). Our results are consistent with those of Nimvari et al. (2004), in finding that the transect method was the most to measure open forest stand characteristics. The results of our study showed that the mean and variance of stand characteristics with transect sampling were near the actual mean and variance derived from the $100 \%$ survey. The mean for crown canopy (\%) in the transect method was not significantly different from the actual mean derived from $100 \%$ survey $(P=0.432$; Table 5$)$. Also, the estimator $(\mathrm{E} \%)^{2} \times T$ or the transect sampling was lower than for the systematic-random sampling and thus more economical for the Zagros open forest (Table 6), consistent with results of other researchers. Hermandez (1997) showed that the transect sampling method was the best for estimating 
Table 3 Statistical results of two sampling methods

\begin{tabular}{llllrr}
\hline Characteristics & Sampling methods & \multicolumn{1}{l}{ X } & SD & \multicolumn{1}{l}{$S_{\bar{x}}$} & E\% \\
\hline Density $\left(\right.$ tree $\left.\mathrm{ha}^{-1}\right)$ & Transect & 70.182 & \pm 7.064 & \pm 1.161 & 2.808 \\
& Systematic-random & 61.078 & \pm 20.573 & \pm 3.382 & 9.397 \\
Basal area $\left(\mathrm{m}^{2} \mathrm{ha}^{-1}\right)$ & Transect & 14.911 & \pm 2.679 & \pm 0.440 & 5.007 \\
& Systematic-random & 9.847 & \pm 5.751 & \pm 0.945 & 16.286 \\
Crown canopy (\%) & Transect & 35.246 & \pm 13.462 & 2.213 & 6.279 \\
& Systematic-random & 27.023 & \pm 18.643 & \pm 3.065 & 19.248 \\
\hline
\end{tabular}

$\bar{x}$ mean, $S D$ standard deviation, $S_{\bar{x}}$ standard error, $E \%$ sampling error
Table 4 Comparison of results from the two sampling methods based on paired $t$-test

\begin{tabular}{llcl}
\hline Characteristics & Transect & Systematic-random & $P$ \\
\hline Density $\left(\right.$ tree ha $\left.\mathrm{ha}^{-1}\right)$ & 70.182 & 61.078 & $0.008^{*}$ \\
Basal area $\left(\mathrm{m}^{2} \mathrm{ha}^{-1}\right)$ & 14.911 & 9.847 & $0.000^{*}$ \\
Crown canopy $(\%)$ & 35.246 & 27.023 & $0.011^{*}$ \\
\hline
\end{tabular}

* Values differed significantly at the 0.05 probability level

Table 5 Comparison of the two sampling methods with the actual means

\begin{tabular}{lll}
\hline Characteristics & Methods & $P$ \\
\hline Density $\left(\right.$ tree $\left.\mathrm{ha}^{-1}\right)$ & Transect & $0.000^{*}$ \\
& Systematic-random & $0.000^{*}$ \\
Basal area $\left(\mathrm{m}^{2} \mathrm{ha}^{-1}\right)$ & Transect & $0.007^{*}$ \\
& Systematic-random & $0.000^{*}$ \\
Crown canopy (\%) & Transect & 0.432 \\
& Systematic-random & $0.007^{*}$ \\
\hline
\end{tabular}

* Values differed significantly at the 0.05 probability level

Table 6 Comparison of the two sampling methods based on $(\mathrm{E} \%)^{2} \times T$

\begin{tabular}{llrlr}
\hline Methods & Characteristics & $(\mathrm{E} \%)^{2}$ & \multicolumn{1}{l}{$T$} & $(\mathrm{E} \%)^{2} \times T$ \\
\hline Systematic-random & Density & 125.57 & 248.35 & $31,186.23$ \\
& Basal area & 371.71 & 332.42 & $123,563.83$ \\
& Canopy & 523.49 & 412.23 & $215,798.28$ \\
Transect & Density & 9.98 & 209.43 & 2090.11 \\
& Basal area & 41.08 & 243.09 & 9986.10 \\
& Canopy & 10.69 & 357.20 & 3818.40
\end{tabular}

E\% accuracy of sampling methods, $T$ total time of sampling methods (min)

density and crown canopy (\%) in conifer forests. Alijanpour et al. (2004) estimated the number of trees $\mathrm{ha}^{-1}$ and basal area using three sampling methods including circular, quadratic and transect methods in the Aras-baran forest in
Iran and showed that the transect sampling method was the most appropriate. However, when Lisa (2002) assessed the efficiency of strip and transect sampling methods for 17 conifer stands, there was no significant difference in the estimates from the two methods. The results of our study agreed with those of Salmanian Chafjiri (2004) and Fallah et al. (2012). The transect sampling method with a fixed number of trees was statistically defensible and practical for quantitating tree characteristics in an open forest such as the Zagros forest areas.

Open Access This article is distributed under the terms of the Creative Commons Attribution 4.0 International License (http://crea tivecommons.org/licenses/by/4.0/), which permits unrestricted use, distribution, and reproduction in any medium, provided you give appropriate credit to the original author(s) and the source, provide a link to the Creative Commons license, and indicate if changes were made.

\section{References}

Alijanpour A, Zobeiri M, Marvi-Mohajer MR, Zargham N (2004) An investigation of the Best Statistic Sampling Method in forest of Aras-baran. Iran J Nat Res 56(4):397-405

Barbour MG, Burk JH, Pitts WD (1987) Terrestrial plant ecology. The Benjamin/Cummings Publishing Company, Menlo Park, p 604

Bonyad AE (2015) Forest sampling methods. Guilan University Press, Sowmeh Sara

Clapham AR (1932) The form of the observational unit in quantitative ecology. J Ecol 20:192-197

Fallah A, Zobeiri M, Rahimipour Sisakht A, Naghavi H (2012) Investigation on four sampling methods for canopy cover estimation in Zagros Oak Forests, Case study: Mehrian Forests of Yasuj City. Iran J For Poplar Res 20(2):194-203

Hall JB (1991) Multiple-nearest-tree sampling in an ecological survey of Afromontane catchments forests. For Ecol Manag 42:245-266

Heidari RH, Zobeiri M, Namiranian M, Sobhani H (2009) Comparison of circular plot and transect sampling methods in the Zagros Oak Forest (case study: educational and research forest of Razi University, Kermanshah Province). Iran J For Poplar Res 17(3): 359-368

Hermandez M (1997) Line sampling for assessment of tree tows and forest stretches in inventories. http://www.ffu.uni

Husch B, Miller CI, Beers TW (1982) Forest mensuration. Roland Press Company, New York

Kleinn C, Vilcko F (2006) A new empirical approach for estimation in k-tree sampling. For Ecol Manag 237:522-533 
Krebs CJ (1999) Ecological methodology. The Benjamin/Cummings Publishing Company, Menlo Park, p 620

Laycock WA, Batcheler CL (1975) Comparison of distance measurement techniques for sampling tussock grassland species in New Zealand. J Range Manag 28:235-239

Lessard VC, Drummer TD, Reed DDA (2002) Precision of density estimates from fixed-radius plots compared to n-tree distance sampling. For Sci 48:1-6

Lisa JB (2002) Accuracy and efficiency of methods to sample logs wildlife research and management. USDA forest general technical reports, Pacific Southwest Research Station, p 181-185

Loetsch F, Zohrer F, Haller KE (1973) Forest inventory. BLV Verlagsgesellschaft, Munchen, Germany, Munchen, p 905

Marvi-Mohajer MR (2007) Silviculture. University of Tehran, Tehran, p 387

Mirzaei M, Bonyad AE (2014) Defining the most appropriate transect method for estimation of basal area: case study in Dalab Forests, Ilam Province. Iran J For Poplar Res 22(1):90-98

Newton AC (2007) Forest ecology and conservation a handbook of techniques. Oxford University Press, London, p 454

Nimvari JE, Zobeiri M, Sobhani H, Zangeneh HP (2004) A comparison of randomized-systematic sampling with circle shape plot and transect method based on precision and cost: case study in Sorkhedizeh of Kermanshah. Iran J Nat Res 56(4):383-395

Parker KR (1979) Density estimation by variable area transects. J Wildl Manag 43(2):484-492
Picard N, Kouyate AM, Dessard H (2005) Tree density estimations using a distance method in Mali Savanna. For Sci 31:7-18

Pique M, Obon B, Condes S, Saura S (2011) Comparison of relascope and fixed-radius plots for the estimation of forest stands variables in northeast Spain: an inventory simulation approach. Eur J For Res 130:851-859

Rostami A, Heidari H (2009) Typology of forest stands and evaluation of their overall status in natural forest of Dalab Region, Ilam Province. J Agric Sci Nat Resour 15(6):274-277

Salmanian Chafjiri A (2004) Comparison of transect and systematic random with rectangular plots sampling methods in the Zarbin reservation of Hassan Abad Chaloos. MSc Thesis, Faculty of Natural Resources, University of Tehran, Tehran, $\mathrm{p} 49$

Scott CT, Gove JH (2002) Forest inventory. In: El-Shaarawi AH, Piegorsch WW (eds) Encyclopedia of environmetrics. Wiley, p 814-820

Sheil D, Ducey MJ, Sidiyasa K, Samsoedin I (2003) A new type of sample unit for the efficient assessment of diverse tree communities in complex forest landscapes. J Trop For Sci 15:117-135

Sutherland W (2008) Ecological census techniques a handbook, 2nd edn. Cambridge University Press, London, p 432

Zobeiri M (2005) Forest inventory (measurement of tree and forest). University of Tehran Press, Tehran, p 401

Zobeiri M (2007) Forest biometry. University of Tehran Press, Tehran, p 411 